ARTICLE

\title{
Gold catalysts containing interstitial carbon atoms boost hydrogenation activity
}

\author{
Yafei Sun ${ }^{1,6}$, Yueqiang Cao (id ${ }^{2,6}$, Lili Wang ${ }^{1,6}$, Xiaotong Mu1, Qingfei Zhao', Rui Si ${ }^{3}$, Xiaojuan Zhu', \\ Shangjun Chen ${ }^{1}$, Bingsen Zhang (iD ${ }^{4}$, De $\mathrm{Chen}^{5} \&$ Ying Wan (iD) ${ }^{1 \times}$
}

Supported gold nanoparticles are emerging catalysts for heterogeneous catalytic reactions, including selective hydrogenation. The traditionally used supports such as silica do not favor the heterolytic dissociation of hydrogen on the surface of gold, thus limiting its hydrogenation activity. Here we use gold catalyst particles partially embedded in the pore walls of mesoporous carbon with carbon atoms occupying interstitial sites in the gold lattice. This catalyst allows improved electron transfer from carbon to gold and, when used for the chemoselective hydrogenation of 3-nitrostyrene, gives a three times higher turn-over frequency (TOF) than that for the well-established $\mathrm{Au} / \mathrm{TiO}_{2}$ system. The $d$ electron gain of $\mathrm{Au}$ is linearly related to the activation entropy and TOF. The catalyst is stable, and can be recycled ten times with negligible loss of both reaction rate and overall conversion. This strategy paves the way for optimizing noble metal catalysts to give an enhanced hydrogenation catalytic performance.

\footnotetext{
${ }^{1}$ Key Laboratory of Resource Chemistry of Ministry of Education, Shanghai Key Laboratory of Rare Earth Functional Materials, and Department of Chemistry, Shanghai Normal University, 200234 Shanghai, China. ${ }^{2}$ State Key Laboratory of Chemical Engineering, East China University of Science and Technology, 200237 Shanghai, China. ${ }^{3}$ Shanghai Synchrotron Radiation Facility, Shanghai Institute of Applied Physics, Chinese Academy of Sciences, 201204

Shanghai, China. ${ }^{4}$ Shenyang National Laboratory for Materials Science, Institute of Metal Research, Chinese Academy of Sciences, 110016 Shenyang, China.

${ }^{5}$ Department of Chemical Engineering, Norwegian University of Science and Technology, N-7491 Trondheim, Norway. ${ }^{6}$ These authors contributed equally:

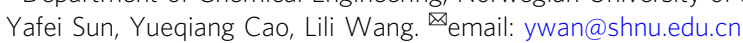


G old is among the least active metals toward molecules at a solid-liquid or solid-gas interface. For example, it has the highest energy barrier for the dissociation of $\mathrm{H}_{2}$ and the least stable chemisorption state ${ }^{1-3}$. This inertness has been attributed to the full filling of the antibonding $d$ state on adsorption and the small orbital overlap with the adsorbate according to the $d$-band model ${ }^{1,4}$. Therefore, when gold is loaded on a less-active support, such as silica and activated carbon, the catalyst shows a very weak catalytic hydrogenation activity due to the fact that the net atomic charge transfer to the substrate or host atoms is very small ${ }^{5}$. Taking into account the fact that activated carbon is the most frequently used carrier for metal catalysts in industry, the activation of, or the charge transfer into gold atoms, which are supported on activated carbon, and its relationship with the catalytic hydrogenation activity are of significant importance but have been seldom reported.

It has been reported that the gold catalysts can sometimes show hydrogenation activity when gold nanoparticles or atoms are supported on reducible oxides ${ }^{6,7}$. In particular, when supported on $\mathrm{TiO}_{2}, \mathrm{Fe}_{2} \mathrm{O}_{3}$, etc., gold nanoparticles exhibit high chemoselectivity in reducing a nitro group, whereas other reducing functions are seen in nitroaromatics ${ }^{8-11}$. In these cases, the structure properties of the oxides, including size, phase, exposed crystal plane, oxidation state, reducibility, perimeter sites, etc., have dominant effects on the electronic structure of the nanoparticles ${ }^{12}$. These factors result in the complexity of solid catalysts, and even contradictory results. For example, density functional theory (DFT) calculations show that gold atoms that are neutral or with a net charge close to zero can be active for $\mathrm{H}_{2}$ dissociation, and are usually located at low-coordinated corner or edge positions that do not directly bond to the support. However, the dissociation of molecular hydrogen at the perimeter sites of $\mathrm{Au} / \mathrm{TiO}_{2}{ }^{13,14}$, and a pronounced charge transfer from defect sites on the reduced $\mathrm{TiO}_{2}(110)$ surface to Au clusters have also been reported ${ }^{6,9,15-17}$. The charge transfer calculations, however, are not in good agreement with each other. Some researchers have reported that spectroscopic characterization shows that cationic $\mathrm{Au}$ species such as $\mathrm{Au}^{+}$and $\mathrm{Au}^{3+}$ are present at the perimeter interface ${ }^{18}$, while negatively charged Au clusters at metal/oxide interfaces have also been confirmed ${ }^{19}$. This complexity limits the correlation of the electronic structure with the catalytic properties, and industrial applications. It has been shown that there is no direct correlation between the number of cationic or anionic $\mathrm{Au}$ species and catalytic activity ${ }^{20}$.

The motivation for the use of ordered mesoporous carbon as the support is because it is a kind of activated carbon, and porous carbon-supported noble metal catalysts play an important role in the fine chemicals industry, and also have an indispensable role in new energy technologies, such as biomass conversion and fuel cells $^{21,22}$. Their synthesis involves hydrothermal synthesis, polymerization for phenolic resins, and carbonization, all of which have been realized on an industrial scale ${ }^{23}$. The carbonization step with metal species is analogous to the growth of carbon nanotubes by catalytic chemical vapor deposition ${ }^{24}$. Carbon atoms deposit on the transition metal surface such as iron and palladium, and diffuse into the lattice ${ }^{25}$. Schlögl and coworkers reported the formation of interstitial C atoms in a Pd catalyst during the hydrogenation of alkyne, which showed significant promotion in the selectivity for olefins ${ }^{26}$. DFT calculations confirmed the presence of surface and subsurface carbon atoms in $\mathrm{Pd}^{27,28}$. Our group found that carburizing a Pd catalyst with interstitial $\mathrm{C}$ atoms produces strong inhibition of the adsorption of thiourea, a strong adsorbate ${ }^{29}$. We speculate that the formation of interstitial $\mathrm{C}$ in the Au lattice will modify its electronic properties although this has not been reported in experiment ${ }^{30}$.

Here, uniform gold nanoparticles with carbon atoms occupying interstitial sites in the lattice $(\mathrm{C}-\mathrm{Au})$, supported on ordered mesoporous carbon have been synthesized. Combining X-ray absorption spectroscopy (XAS) with X-ray photoelectron spectroscopy (XPS) analysis, we are able to measure the $d$-electron gain of Au. There is a linear relationship between the $d$-electron gain of gold and its activation entropy $\left(\Delta S^{0 *}\right)$, and catalytic
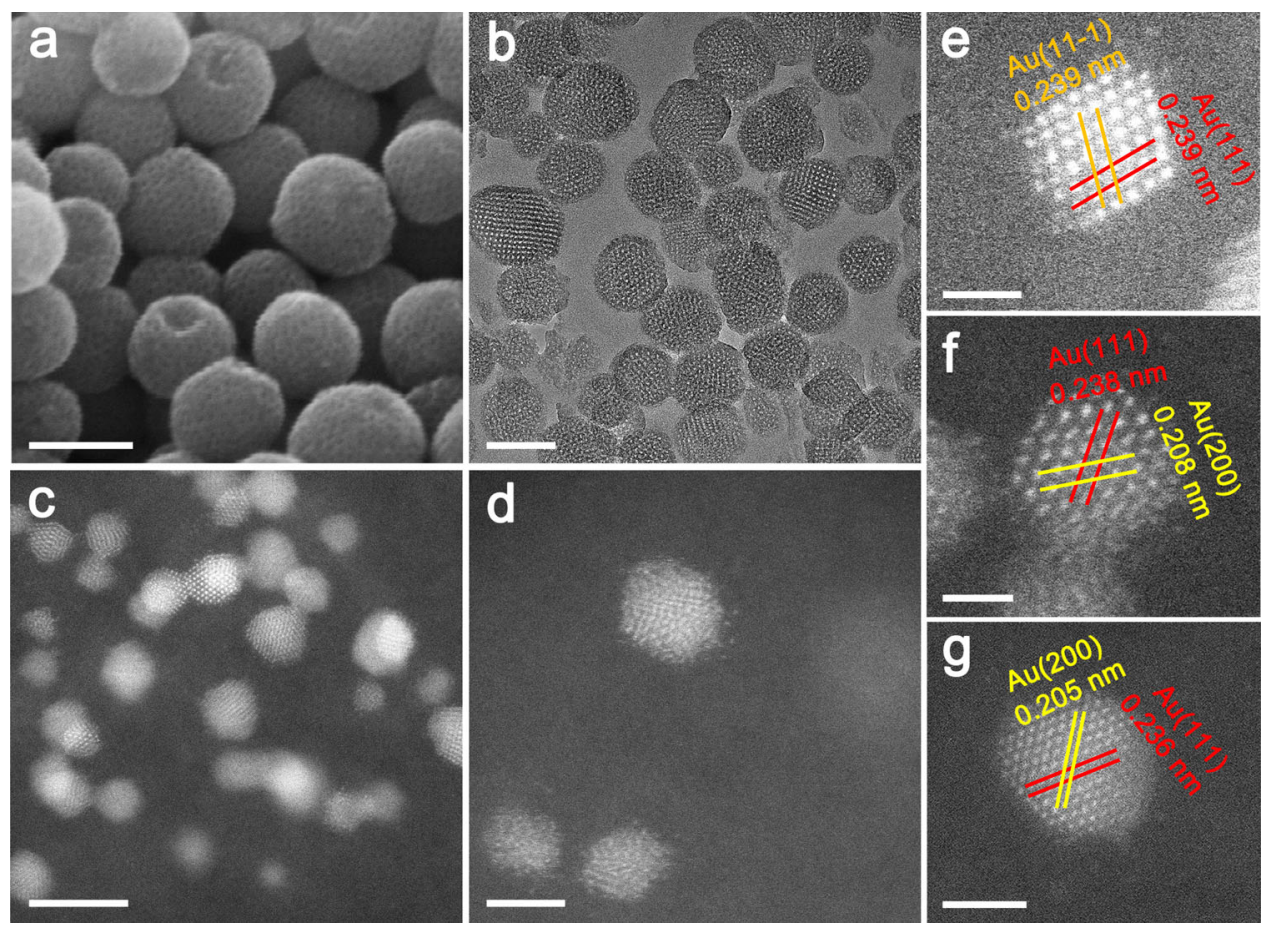

Fig. 1 Electron micrographs. a Representative HRSEM image, b TEM image of an ultrathin section, c, d HAADF-AC-STEM images for fresh C-Au-2.4/ OMC; AC-STEM images for fresh e C-Au-1.6/OMC, f C-Au-2.4/OMC, and $\mathbf{g}$ C-Au-3.9/OMC. The scale bar is $100 \mathrm{~nm}$ for (a, b), $5 \mathrm{~nm}$ for (c), $2 \mathrm{~nm}$ for $(\mathbf{d}, \mathbf{g})$, and $1 \mathrm{~nm}$ for $(\mathbf{e}, \mathbf{f})$ 
activity in the chemoselective hydrogenation of the nitro group in substituted nitroaromatics. The electron gain of 0.192 of $\mathrm{Au}$ for the $\mathrm{C}-\mathrm{Au}-1.6 / \mathrm{OMC}$ catalyst is much higher than that of the wellknown $\mathrm{Au} / \mathrm{TiO}_{2}$ catalyst, showing an almost three times higher turn-over frequency (TOF) value than the latter. This strategy paves the way for optimizing noble metal catalysts to give them enhanced hydrogenation catalytic performance.

\section{Results}

Structure of supported gold interstitial nanocatalysts. A series of gold interstitial nanocatalysts supported on ordered mesoporous carbonaceous materials $(\mathrm{C}-\mathrm{Au} / \mathrm{OMC})$ with different gold nanoparticle sizes was produced by hydrothermal synthesis, polymerization of the phenolic resins, and carbonization. Wide-angle X-ray diffraction (WAXRD) patterns show broad diffraction peaks at $\sim 23^{\circ}$, which is attributed to the amorphous carbonaceous framework, and at $\sim 38.02^{\circ}$, which is attributed to the growth of very small $\mathrm{Au}$ nanoparticles or the presence of amorphous Au species ${ }^{31}$ (Supplementary Fig. 1). High-resolution scanning electron microscope (HRSEM) images show that all the studied $\mathrm{C}-\mathrm{Au} / \mathrm{OMC}$ catalysts have a spherical morphology with an average diameter of $90 \mathrm{~nm}$ (Fig. 1a, Supplementary Fig. 2). Ordered mesopores can be clearly seen on the exposed hemispheres, reflecting an open pore structure on the surface. Nanospheres with open and small mesopores have been verified to eliminate the diffusion limitation especially for reactions involving large molecules ${ }^{31}$. A transmission electron microscope (TEM) image (Fig. 1b) taken from an ultrathin section of the $\mathrm{C}-\mathrm{Au}-2.4 / \mathrm{OMC}$ shows spherical carbon particles about $100 \mathrm{~nm}$ in diameter that appear to contain ordered mesopores (Supplementary Fig. 3). Gold nanoparticles with a uniform size are located inside the structure, and their size is estimated to range from 1.6 to $9.0 \mathrm{~nm}$. Interestingly, semi-exposed gold nanoparticles can be clearly observed. The similar results have also been found in AuPd nanoparticles partially embedded in the pore walls of ordered mesoporous carbon ${ }^{32}$. Nanoparticles with uniform sizes can also be clearly observed in large areas in high-angle annular dark-field spherical aberration corrected-scanning transmission electron microscope (HAADF-AC-STEM) images (Fig. 1c, d and Supplementary Fig. 4). HAADF-STEM images were also taken for C-Au-2.4/OMC (Supplementary Fig. 5). There are more bright particles in the centers of the circles than at the edges, implying the presence of nanoparticles inside the spheres. It should be mentioned that isolated gold atoms or dimers are not present even with a particle size as small as $1.6 \mathrm{~nm}$.
Therefore, the catalytic activity is exclusively due to the nanoparticles. The diffractogram of the $\mathrm{Au}$ particles, shows an increasing (111) spacing from $2.35 \AA$ in a typical pure Au foil, to $2.36,2.38$, and $2.39 \AA$ in the studied catalysts with Au particle sizes of $3.9,2.4$, and $1.6 \mathrm{~nm}$, respectively, as measured from the AC-STEM images (Fig. 1e-g). It is well-known that lattice contraction occurs in small nanoparticles or clusters, and is related to a higher proportion of outer shell undercoordinated atoms with respect to fully coordinated inner shell atoms and is proportional to the reciprocal of the particle size $(2.75 \%$ contraction for $2.0 \mathrm{~nm}$ nanoparticles) ${ }^{33}$. Therefore, increased lattice fringe separation for the $\mathrm{C}$-modified gold nanoparticles might be related to the dissolution of $\mathrm{C}$ atoms in $\mathrm{Au}$, and their occupation of interstitial sites in the Au lattice. This effect increases with smaller particle size.

Although carbon solubility in $\mathrm{Au}$ is low, $s p^{2}$-bonded structures may nucleate on the $\mathrm{Au}$ surface for the growth of lowdimensional carbon materials including carbon nanotubes, graphene, etc. ${ }^{34,35}$. In fact, gold has a eutectic alloy phase diagram with carbon, and the carbon concentration in bulk Au at the eutectic point is $\sim 0.08$ at $\%{ }^{36}$. Specifically, the $\mathrm{C}$ adatom diffusion barrier is low for $\mathrm{Au}$, and a significant acceleration of the diffusion step can be achieved when a monoatomic carbon precursor (e.g., $\mathrm{CH}_{4}$ ) is used ${ }^{37}$. In the present synthesis, the decomposition of phenolic resins and a triblock copolymer could generate small molecules including $\mathrm{CH}_{4}$ at elevated temperatures $^{32}$. The carbon atoms might preferentially precipitate on the $\mathrm{Au}$ particle surface because the surface tension of graphite is smaller than that of $\mathrm{Au}^{38}$. As a consequence, carbon atoms continuously adsorb on, and quickly diffuse into the surface of the $\mathrm{Au}$ catalyst ${ }^{34}$. The carbon solubility in the particle is inversely related to its size, and is estimated to increase by 12 times as the particle size decreases from 9.0 to $1.6 \mathrm{~nm}^{34}$. This solubility apparently correlates with the lattice expansion as measured from the AC-STEM images, confirming carbon dissolution in the $\mathrm{Au}$ lattice. It should be mentioned that the observed lattice expansion is small possibly due to the relatively low $\mathrm{C}$ solubility and the intrinsic lattice contraction in small size particles. However, a continuous exchange of $\mathrm{C}$ atoms in $\mathrm{Au}$ between surface and subsurface has been reported so that a dynamic equilibrium is established. The mobility of carbon in the lattice may cause residual vacancies and in turn produce a relatively uniform lattice expansion ${ }^{39}$. Indeed, on one occasion an increasing concentration of $\mathrm{CH}_{4}$ was fed into the furnace, and graphene sheets were formed and covered the Au surface (Supplementary Fig. 6).
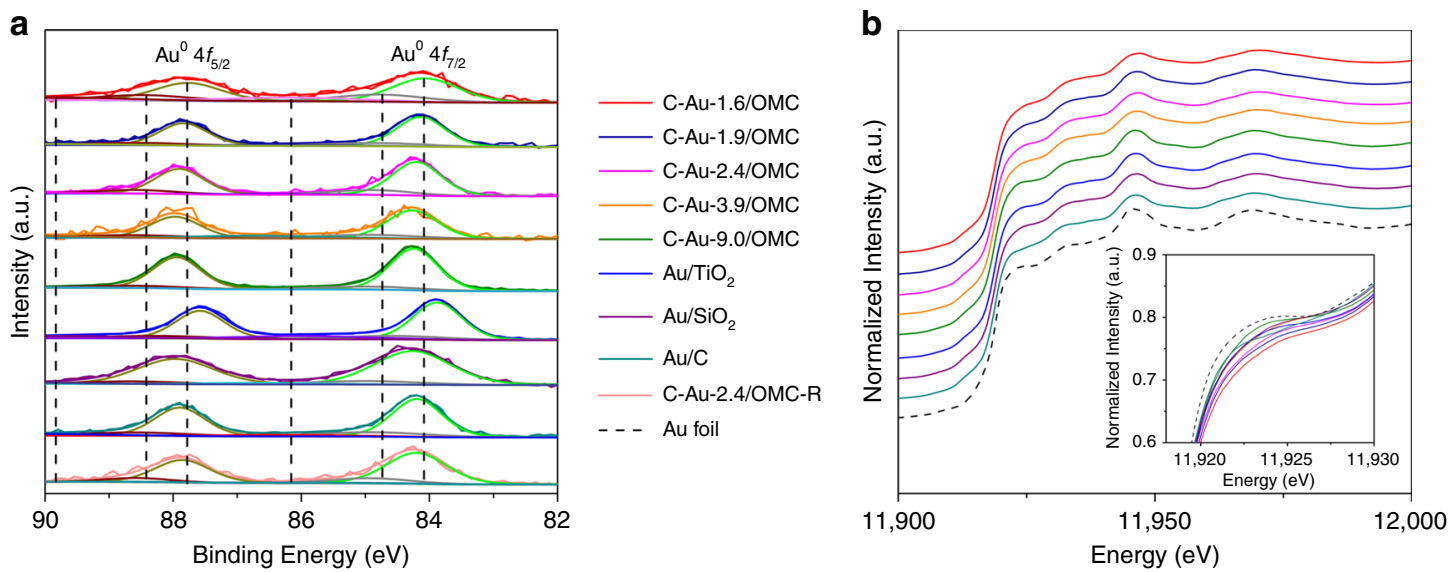

Fig. 2 Electronic properties. a XPS spectra of the Au $4 f$ level; and $\mathbf{b} X A N E S$ spectra of the Au $L_{3}$-edge for Au nanocatalysts containing interstitial carbon supported on ordered mesoporous carbon. $\mathrm{C}-\mathrm{Au}-2.4 / \mathrm{OMC}-\mathrm{R}$ represents the catalyst after being used in five runs. For comparison, commercial $\mathrm{Au} / \mathrm{TiO}$, $\mathrm{Au} / \mathrm{SiO}_{2}$, and $\mathrm{Au} / \mathrm{C}$ were also investigated. 
Pseudo-type-I $\mathrm{N}_{2}$ sorption isotherms with capillary condensation at low pressures are detected for all the catalysts studied, similar to the isotherms of pristine mesoporous carbon nanospheres and typical of the isotherms of small mesopores (Supplementary Fig. 7). The pore volumes and the Brunauer-Emmett-Teller (BET) surface areas are close to those for pristine OMC and are $\sim 0.56 \mathrm{~cm}^{3} \mathrm{~g}^{-1}$ and $594 \mathrm{~m}^{2} \mathrm{~g}^{-1}$ (Supplementary Table 1), respectively.

For comparison, commercial supported catalysts including $\mathrm{Au} /$ $\mathrm{TiO}_{2}, \mathrm{Au} / \mathrm{SiO}_{2}$, and $\mathrm{Au} / \mathrm{C}$ were also used as catalysts, with gold particle diameter mode values of $4.1,5.8$, and $6.3 \mathrm{~nm}$ (Supplementary Fig. 8, and Table 1), respectively. The gold nanoparticles are loaded on the titania surface and inside the pores of porous silica and carbon.

Electronic properties. Figure $2 \mathrm{a}$ shows measured and fitted $\mathrm{Au} 4 f$ XPS spectra for $\mathrm{Au}$ nanocatalysts, and the major peaks for $\mathrm{Au}^{0}$ in all can be fitted with minors of $\mathrm{Au}^{+}$and $\mathrm{Au}^{3+}$, which may originate from undercoordinated sites ${ }^{39}$. There are many possible reasons for the shifts in binding energy. The carrier effect was first investigated by comparing the shifts in the $4 f_{7 / 2}$ level for commercial $\mathrm{Au} / \mathrm{TiO}_{2}, \mathrm{Au} / \mathrm{C}$, and $\mathrm{Au} / \mathrm{SiO}_{2}$, which have similar gold particle sizes with bulk Au. The binding energy value for $\mathrm{Au} / \mathrm{TiO}_{2}$ is lower than for the bulk metal as has been well documented ${ }^{40}$. When the substrate has localized $p$ or $d$ orbitals with binding energies that overlap those of the cluster $d$ orbitals, a reduction in binding energy appears due to charge transfer from the surface to the $\mathrm{Au}$ clusters ${ }^{17,41}$. In contrast, this value is higher for the clusters when the metal-support interaction is weak ${ }^{41}$. It is true that the $\mathrm{Au} 4 f_{7 / 2}$ binding energies increase for commercial $\mathrm{Au} / \mathrm{C}$ and $\mathrm{Au} / \mathrm{SiO}_{2}$. It should be mentioned that this simple isolation effect is an approximation, and is only used to explain the positive shift for Au supported on a carbonaceous support compared to metallic gold. The size effect is then considerable for the gold nanocatalysts containing interstitial $\mathrm{C}$. The $\mathrm{C}-\mathrm{Au}-9.0 / \mathrm{OMC}$ catalyst shows a binding energy for $\mathrm{Au} 4 f_{7 / 2}$ of $84.24 \mathrm{eV}$, close to that for commercial $\mathrm{Au} / \mathrm{C}$. The value increases to $84.27 \mathrm{eV}$ for $\mathrm{C}-\mathrm{Au}$ 3.9/OMC. This shift may be attributed to the particle size effect, which is a final state effect according to the size-dependent electrostatic interaction between the cluster and an escaping photoelectron. It has also been reported that there is a negative core-level shift for the surface atoms of macroscopic Au due to an initial state effect, which is $6 s \rightarrow 5 d$ charge reorganization for the more undercoordinated surface atoms; but for nanoclusters, the initial state shift is mainly overcompensated by the electrostatic final state effect ${ }^{42}$. The present positive shift is in good agreement with the fact that there are shifts to a higher energy for clusters compared to that of the bulk metal. The change is determined by the surface-to-volume ratio, and the photoemission onset is influenced by an initial state effect involving charge transfer ${ }^{41,43}$. However, the binding energy shift does not follow a monotonic increase when further reducing the Au particle size. The Au $4 f_{7 / 2}$ binding energy shifts unexpectedly to $84.20 \mathrm{eV}$ for the $2.4 \mathrm{~nm} \mathrm{Au}$, and finally to $84.07 \mathrm{eV}$ for the $1.6 \mathrm{~nm} \mathrm{Au}$. This distinctive reversal of the binding energy shift in the Au $4 f$ doublet as a function of $\mathrm{Au}$ particle size has been observed in $\mathrm{Au} / \mathrm{TiO}_{2}$ with similarly small changes, and may be assigned to a combined contribution of the charge transfer from surface to clusters, the initial state effect and the electrostatic final state effect ${ }^{17}$. In the present case, $\mathrm{C}$ diffusion that leads to a rearrangement of electron density may be dominant for the charge transfer. Viñes et al. found that the $3 \mathrm{~s}$ core levels of $\mathrm{Au}$ around $\mathrm{C}$ shifts the binding energy to a higher value compared to a pristine $\mathrm{Au}(111)$ surface with no interstitial $\mathrm{C}$, which is an evidence for the redistribution of orbitals ${ }^{30}$. The high energy XPS should be used to give more distinct and direct evidence on interstitial $\mathrm{C}$ in future studies. Here a charge transfer either from the carbon atom or from the $s, p$ electron redistribution of Au may be reasonable.

The X-ray absorption near-edge structure (XANES) spectra of all the studied gold catalysts at the $L_{3}$-edge exhibit three similar peaks at about $40 \mathrm{eV}$ above the edge, indicating a face-centered cubic $(f c c)$ structure in the nanoparticles ${ }^{44}$ (Fig. 2b, Supplementary Fig. 9). The first resonance at the edge arises from $2 p_{3 / 2} \rightarrow$ $5 d_{5 / 2}$ and $5 d_{3 / 2}$ dipole transitions in the vicinity of the Fermi level, the intensity of which is related to the unoccupied densities of $d$ states ( $d$-hole counts $)^{45}$. Weak resonance can be detected in an $\mathrm{Au}$ foil due to $s$ - $p$ - $d$ hybridization, although the $5 d$ orbitals in $\mathrm{Au}$ atoms are nominally full. The supported gold nanoparticles show a decrease in the intensity of this resonance. This could be partially due to the nanosize effect ${ }^{44}$. The $s$ - $d$ hybridization is increased by a stronger $d-d$ interaction in the nanoparticles, leading to an increase of $d$-electron count at the Au sites ${ }^{44}$. When comparing the intensity of the first resonance for $\mathrm{C}-\mathrm{Au}-3.9 /$ $\mathrm{OMC}$, commercial $\mathrm{Au} / \mathrm{TiO}_{2}, \mathrm{Au} / \mathrm{SiO}_{2}$, and $\mathrm{Au} / \mathrm{C}$, which have similar nanoparticle sizes, one observes an obvious difference. This result indicates a change in the surface environment in these catalysts in addition to the nanosize effect. $\mathrm{Au} / \mathrm{TiO}_{2}$ has been reported to have a lower resonance intensity than $\mathrm{Au}$ particles of a similar size in the absence of strong interaction with surface capping molecules ${ }^{46}$. The metal-support interaction results in a negative charge injection into the metal particles by reducible oxides, and a higher increase in $d$-electron density at the gold site compared to bare Au nanoparticles ${ }^{47}$. The number of unoccupied $\mathrm{Au} 5 d_{5 / 2}$ states near the Fermi level is depleted. The interstitial C in the $\mathrm{Au}$ lattice for $\mathrm{C}-\mathrm{Au}-3.9 / \mathrm{OMC}$ can thus account for the further decrease in the white line intensity compared to $\mathrm{Au} / \mathrm{TiO}_{2}$, and the increase of the $d$-electron density. In addition, the white line intensity for C-Au-9.0/OMC with a particle size of $9.0 \mathrm{~nm}$ is even lower than that of commercial $\mathrm{Au} / \mathrm{C}$ with a particle size mode of $6.3 \mathrm{~nm}$, again indicating that the interstitial $\mathrm{C}$ accounts for the electron/hole density at the $5 d$ band, and modifies the electronic behavior of the gold nanoparticles. The area under the white line can be used to count the $d$-charge hole redistribution ${ }^{48}$. A semi-quantitative calculation was made for the $d$-electron gain of the catalysts, which follows the order: $\mathrm{C}-\mathrm{Au}-1.6 / \mathrm{OMC}>$ $\mathrm{C}-\mathrm{Au}-1.9 / \mathrm{OMC}>\mathrm{C}-\mathrm{Au}-2.4 / \mathrm{OMC}>\mathrm{C}-\mathrm{Au}-3.9 / \mathrm{OMC}>\mathrm{Au} / \mathrm{TiO}_{2}$ $>\mathrm{C}-\mathrm{Au}-9.0 / \mathrm{OMC}>\mathrm{Au} / \mathrm{C}>\mathrm{Au} / \mathrm{SiO}_{2}$ (Supplementary Fig. 10, Supplementary Table 2).

The net charge transfer is extremely low $(<0.01 \mathrm{e})$ for commercial $\mathrm{Au} / \mathrm{SiO}_{2}$ and $\mathrm{Au} / \mathrm{C}$ with gold particle sizes of 5.8 and $6.3 \mathrm{~nm}$, respectively, and fewer active carriers, in good agreement with the literature ${ }^{49}$. The increased charge transfer for $\mathrm{C}-\mathrm{Au}-3.9 / \mathrm{OMC}$ with similar particle sizes is exclusively related to the $\mathrm{Au}$ lattice doping by $\mathrm{C}$. In addition, a charge transfer of 0.192 electrons for the $1.6 \mathrm{~nm}$ gold nanoparticles with $\sim 120$ atoms was measured. The $d$-electron gain is reduced to 0.061 electrons for the $\mathrm{C}-\mathrm{Au}$ nanocatalyst with $9.0 \mathrm{~nm}$ gold nanoparticles. The energy levels and the electron occupancy of the valence-shell atomic orbitals of a surface atom will be influenced by the neighboring atoms in the lattice ${ }^{26}$. The localized $e_{\mathrm{g}}$ band in $d$ orbitals with its high density of states is more readily filled than the metallic $t_{2 \mathrm{~g}}$ band by the introduction of $s$ electrons from the interstitial atoms ${ }^{50}$. As a result, a collective contribution from the particle size effect and the charge transfer from carbon or $s$, $p$ electrons to $d$ electrons of $\mathrm{Au}$ in the present $\mathrm{C}$-modified $\mathrm{Au}$ nanocatalysts is assigned to the control of the electron/hole density at the $d$ band, and interstitial carbon is more dominant. Lastly, the charge transfer for $\mathrm{Au} / \mathrm{TiO}_{2}$ is mostly due to the interface interaction. The electron counting is similar to studies based on the well-defined Pt-group catalysts ${ }^{32,51-53}$. A maximum of 0.11 electrons per $\mathrm{Pt}$ atom appears for the Pt deposition with 
30-70 atoms on a well-defined $\mathrm{CeO}_{2}(111)$ surface ${ }^{53}$. The peaks belonging to the higher energy part, are structure dependent, and the intensity can be related to the change in the surrounding atoms for each $\mathrm{Au}$ atom ${ }^{54}$. The shape for the $\mathrm{C}-\mathrm{Au} / \mathrm{OMC}$ samples is close to that of the Au foil, but the intensity is much lower. The $\mathrm{C}-\mathrm{Au}-1.6 / \mathrm{OMC}$ has the minimum intensity. Both the decrease in the number of adjacent $\mathrm{Au}$ atoms and the increase in the number of interstitial carbon atoms may contribute to reducing the intensity.

Selective hydrogenation of 3-nitrostyrene over C-Au/OMC. The catalytic hydrogenation of aromatic nitro compounds is a cleaner option to produce anilines, but the low selectivity when other reducible groups exist in the reactant molecule is still a drawback, due to the strong adsorption of unsaturated groups on the catalyst surface ${ }^{55}$. Increased activity has been demonstrated on $\mathrm{Au} / \mathrm{TiO}_{2}$ for the conversion of nitrostyrene by Corma et al., but the hydrogenation of nitrostyrene by gold nanoparticles supported on activated carbon or silica shows a very low conversion, and produces both the reduction of the $\mathrm{C}=\mathrm{C}$ double bond and nitro functional groups ${ }^{11}$. Therefore, the selective hydrogenation of 3-NS to 3-vinylaniline (3-VA) was chosen as the model reaction for the investigation of the catalytic performance of mesoporous carbon-supported gold nanocatalysts.

The kinetic results in Fig. 3a clearly show that with $\mathrm{C}-\mathrm{Au} /$ OMC catalysts, the conversion plots are almost linear with reaction time for the selective hydrogenation of 3-NS. The TOF value follows the order: $\mathrm{C}-\mathrm{Au}-1.6 / \mathrm{OMC}>\mathrm{C}-\mathrm{Au}-1.9 / \mathrm{OMC}>$ $\mathrm{C}-\mathrm{Au}-2.4 / \mathrm{OMC}>\mathrm{C}-\mathrm{Au}-3.9 / \mathrm{OMC}>\mathrm{C}-\mathrm{Au}-9.0 / \mathrm{OMC}$ (Supplementary Fig. 11). The reference $\mathrm{Au} / \mathrm{TiO}_{2}$ catalyst shows a similar high activity and selectivity values to those reported in the literature ${ }^{6,56}$. Notably, the TOF value for $\mathrm{Au} / \mathrm{TiO}_{2}$ is lower than for $\mathrm{C}-\mathrm{Au}-3.9 / \mathrm{OMC}$ with a similar particle size, while commercial $\mathrm{Au} / \mathrm{C}$ and $\mathrm{Au} / \mathrm{SiO}_{2}$ catalysts, which have $\mathrm{Au}$ particle size modes of 6.3 and $5.8 \mathrm{~nm}$, respectively, show almost no catalytic activity. Therefore, the particle size is possibly not the decisive factor in determining the activity. The selectivities for $\mathrm{C}-\mathrm{Au}-1.6 / \mathrm{OMC}$, $\mathrm{C}-\mathrm{Au}-1.9 / \mathrm{OMC}$, and $\mathrm{C}-\mathrm{Au}-2.4 / \mathrm{OMC}$ are high, reaching $\sim 100 \%$ at a high conversion (Supplementary Fig. 12). For C-Au-3.9/ OMC and C-Au-9.0/OMC, when the conversion is above $80 \%$, the only detectable by-product $(<5 \%)$ is 3-ethylaniline (3-EA), and others, including 3-ethylnitrobenzene and azoxystyrene, are undetectable, analogous to the results over $\mathrm{Au} / \mathrm{TiO}_{2}$ nanocatalysts reported by Corma et al. 6 .

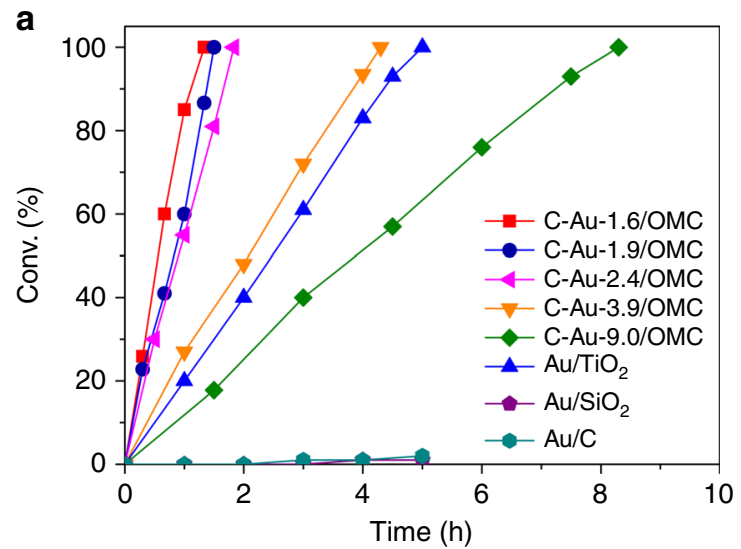

No diffusion phenomena were observed when stirring at a rate of over $500 \mathrm{rpm}$ in the hydrogen reactor (Supplementary Fig. 13). In addition, gold nanocatalysts were synthesized with similar particle sizes $(2.4 \mathrm{~nm})$ but different gold loadings (0.5-0.8 wt\%, Supplementary Fig. 14). Under the conditions we used we have proved that the initial rate of the reaction increases linearly with the concentration of gold in catalysts with similar gold nanoparticle sizes (Supplementary Fig. 15). As a result, diffusion limitation can be excluded ${ }^{57,58}$. The leaching of gold species from the solid catalyst, which can catalyze the hydrogenation has been argued by some researchers. A solid quenching test was performed using mesoporous silica SH-SBA-15 containing mercapto functional groups as the trapping agent. Once the metal species leach into solution, mercapto functional group will trap them, and quench the catalysis by leaching metal species in liquid reactions ${ }^{59}$. The unchanged hydrogenation activity and selectivity in the presence of SH-SBA-15 demonstrates that there is no leaching of gold with the present $\mathrm{C}-\mathrm{Au} / \mathrm{OMC}$ catalysts regardless of $\mathrm{Au}$ particle size, and solubilized gold in solution during the reaction and redeposition on the carrier surface after the reaction can be excluded (Supplementary Fig. 16). The reusability of $\mathrm{C}-\mathrm{Au}-2.4 / \mathrm{OMC}$ was also tested. Both the initial reaction rate $\left(r_{0}\right)$ and turn-over number in ten successive runs remained almost the same (Supplementary Fig. 17), indicating the number of active centers does not significantly change. The reused catalysts were characterized. The XPS spectrum shows no distinct changes compared with the fresh catalyst. The Au concentration in the re-used catalyst after ten runs remained at $0.91 \mathrm{wt} \%$, also similar to that determined for the fresh catalyst. In addition, the average Au particle size for the re-used catalyst also remained almost unchanged, as shown by TEM images (Supplementary Fig. 18). In these cases, the leaching and/or aggregation of gold nanoparticles can be excluded. A surface reaction on the Au nanoparticles instead of a reaction in solution catalyzed by leaching $\mathrm{Au}$ is the best model for the present reaction. By comparison, the commercial $\mathrm{Au} / \mathrm{TiO}_{2}$ catalyst may undergo aggregation during the reaction. After five runs, the gold in the $\mathrm{Au} / \mathrm{TiO}_{2}$ catalyst appears to aggregate during the reaction, with the nanoparticle diameter increasing from 4.1 to $8.0 \mathrm{~nm}$ after five runs, and the TOF decreased to $59 \mathrm{~h}^{-1}$ (Supplementary Fig. 11).

To study the kinetics, several experiments were carried out. First, the initial reaction rate was measured at different 3-NS levels under constant $\mathrm{H}_{2}$ pressure and temperature (Supplementary Fig. 19a). A constant $r_{0}$ was observed in the range

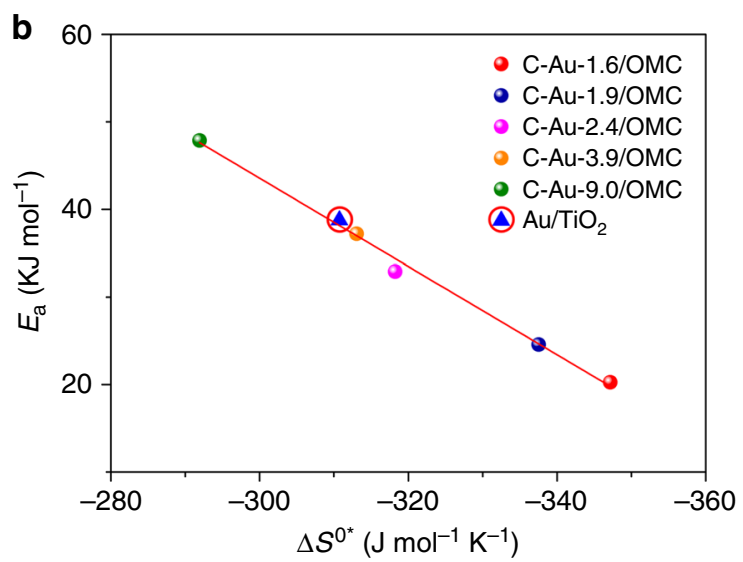

Fig. 3 Kinetics analysis. a 3-NS conversion as a function of time with the following reaction conditions over $\mathrm{C}-\mathrm{Au}$ nanoparticles of different sizes supported on ordered mesoporous carbon. The reaction conditions were: $0.78 \mu \mathrm{mol}$ of $\mathrm{Au} ; 0.41 \mathrm{mmol}$ of substrate; $5 \mathrm{~mL}$ of ethanol; $140{ }^{\circ} \mathrm{C} ; 4.0 \mathrm{MPa} \mathrm{H}_{2}$.

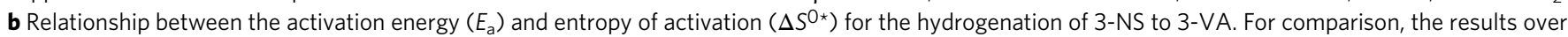
commercial $\mathrm{Au} / \mathrm{TiO}_{2}, \mathrm{Au} / \mathrm{SiO}_{2}$, and $\mathrm{Au} / \mathrm{C}$ are also given. 


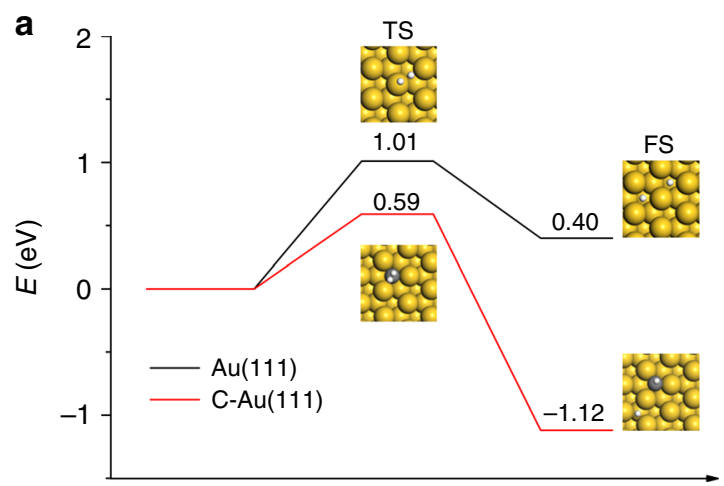

Reaction Coordinate

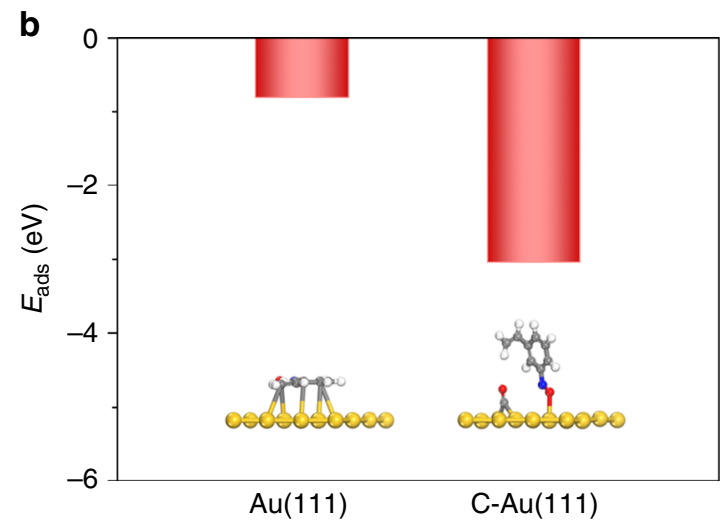

Fig. 4 DFT calculations. a Energy profiles for the dissociation of $\mathrm{H}_{2}$ at Au surfaces. The black line belongs to heterolytic dissociation on clean Au(111), and the red one to heterolytic dissociation on C-modified Au(111). The zero-point energy correction is included in the profile. b Adsorption modes of 3-NS and its corresponding energies on clean $\mathrm{Au}(111)$ and $\mathrm{C}$-modified $\mathrm{Au}(111)$.

0.0514-0.095 $\mu \mathrm{mol} \mathrm{L} \mathrm{L}^{-1}$, implying that the adsorption/desorption equilibrium of 3-NS has a minor effect on the kinetics. This result, together with the fact that linear 3-NS conversion vs time plots for all studied catalysts were observed as mentioned above, suggests a zero order for 3 -NS in the rate equation. Second, experiments were performed at different initial hydrogen pressures while keeping the 3-NS concentration, the reaction temperature and the amount of catalyst constant. These showed a linear increase in $r_{0}$ with increasing $\mathrm{H}_{2}$ pressure within the range of pressures studied (Supplementary Fig. 19b). Third, the rate constant $(k)$ for 3 -VA formation with $\mathrm{H}_{2}$ was compared with that using $\mathrm{D}_{2}$ to investigate the rate-determining step. The experimentally observed $k_{\mathrm{H}} / k_{\mathrm{D}}$ ratio is $\sim 2.7$. This obvious isotopic effect confirms $\mathrm{H}_{2}$ dissociation as the rate-determining step. All these results are in good agreement with those in the literature for $\mathrm{Au} /$ $\mathrm{TiO}_{2}{ }^{60}$. 3-NS and $\mathrm{H}_{2}$ react after adsorbing on active sites with the same nature, but $\mathrm{H}_{2}$ dissociation is the rate limiting step of the reaction (Supplementary information methods). The overall reaction is first order for $\mathrm{H}_{2}$, at least for high concentrations of 3-NS. The Arrhenius plots shown in Supplementary Fig. 20 were obtained by calculating $k$ at different reaction temperatures. The apparent activation energies $\left(E_{\mathrm{a}}\right)$, and the apparent entropies changes $\Delta S^{0 *}$ for the catalysts were estimated based on the Arrhenius equation and transition state theory (Supplementary information methods). The activation entropy reflects the freedom of the system, using the hypothesis that catalysis is related to the surface intermediate with the promotion of an electron from the adsorbate to a localized band of the solid ${ }^{61}$. The increase in the binding energy of the molecule or functional group to the surface leads to a greater restriction on vibrational and rotational freedom ${ }^{62}$. A linear relationship is observed for $E_{\mathrm{a}}$ and $\Delta S^{0 *}$ for the $\mathrm{C}-\mathrm{Au} / \mathrm{OMC}$ catalysts with various nanoparticle sizes, which is called the compensation effect (Fig. 3b $)^{63}$. This result implies a relationship between the adsorption configuration and electronic properties, and the catalytic activity. Notably, the commercial Au/ $\mathrm{TiO}_{2}$ catalyst follows the same trend.

DFT calculations. The diffusion of $\mathrm{C}$ atoms into interstitial sites of the Au lattice was also examined by DFT calculations. The most favorable absorption configuration and energies for a single carbon atom on the close-packed $\mathrm{Au}(111)$ and stepped (211) facets are summarized in Supplementary Figs. 21-22. Carbon atoms preferentially adsorb on $f c c$ threefold hollow sites on the surface and tetrahedral interstices on the subsurface for $\mathrm{Au}(111)$. Hexagonal close-packed $(h c p)$ threefold hollow sites and tetrahedral interstices are the most preferred by $\mathrm{C}$ species on the $\mathrm{Au}$
(211) surface and subsurface, respectively. Since Au is the most noble metal and has an extremely high dissociation energy barrier for $\mathrm{H}_{2}$, we first compare the dissociation of $\mathrm{H}_{2}$ on a clean $\mathrm{Au}(111)$ surface with one modified with C (Fig. 4a). As expected, on clean $\mathrm{Au}(111)$, one $\mathrm{H}$ atom is above the $\mathrm{Au}$ atom, and the other $\mathrm{H}$ atom is at the site bridging two $\mathrm{Au}$ atoms. The energy barrier of $\mathrm{H}_{2}$ dissociation of $1.01 \mathrm{eV}$ and the adsorption energy, with respect to $\mathrm{H}_{2}$, is around $0.40 \mathrm{eV}$, close to the reference value ${ }^{64}$. When carbon diffuses into the $\mathrm{Au}(111)$ surface, the $\mathrm{H}_{2}$ can be activated only by the $\mathrm{C}$ atom, and both $\mathrm{H}$ atoms are adsorbed on the $\mathrm{C}$ atom, reducing the activation barrier to $0.59 \mathrm{eV}$, implying a lower energy process. The final state shows one $\mathrm{H}$ atom being anchored on a carbon atom, and the other on an $\mathrm{Au}$ atom, with the adsorption energy being little changed. These results indicate that the heterolytic dissociation of $\mathrm{H}_{2}$ by $\mathrm{Au}$ and $\mathrm{C}$ is dominant for the hydrogenation, similar to that by perimeter sites over $\mathrm{Au} / \mathrm{TiO}_{2}{ }^{14}$. It should be mentioned that the subsurface carbon atom on $\mathrm{Au}$ (111) diffuses to the surface as a result of $\mathrm{H}$ adsorption, in good agreement with the dynamic mobility of $\mathrm{C}$ atoms on transition metal (111) surfaces under working conditions of low $\mathrm{C}$ coverage $^{39}$. As a result, the presence of subsurface $C$ would facilitate the mobility of carbon in the lattice, possibly to some C-free areas of the surface ${ }^{39}$. This would further enhance the $\mathrm{H}$ adsorption.

DFT calculations show that parallel adsorption with the shortest average distance between adsorbate the $\mathrm{Au}(111)$ and $\mathrm{Au}(211)$ surfaces is most favorable (Fig. 4b, Supplementary Fig. 23). The chemical bonding between the functional groups of nitro, phenyl, and vinyl group in 3-NS and clean $\mathrm{Au}(111)$ and $\mathrm{Au}$ (211) surfaces is negligible. The calculated adsorption energies are low, primarily due to physical adsorption, in good agreement with nitrobenzene adsorption on $\mathrm{Au}$ surfaces ${ }^{15}$. This result predicts that 3-nitrostyrene interacts weakly with commercial Au/ $\mathrm{C}$ and $\mathrm{Au} / \mathrm{SiO}_{2}$ in which gold nanoparticles have weak interactions with the less-active supports, and the selectivity is low for the hydrogenation of nitro groups and the $\mathrm{C}=\mathrm{C}$ double bond due to negligible preferential adsorption toward one or the other, in agreement with experiment. A completely different situation occurs when 3-NS interacts with Au surfaces containing interstitial $\mathrm{C}$. The most favorable adsorption configuration for 3NS over the $\mathrm{C}-\mathrm{Au}(111)$ and $\mathrm{C}-\mathrm{Au}(211)$ surfaces is perpendicular adsorption. On the $\mathrm{C}-\mathrm{Au}(111)$ surface, one of the $\mathrm{N}-\mathrm{O}$ bonds breaks with $\mathrm{O}$ on the carbon atom, and the other $\mathrm{O}$ on the nonneighboring $\mathrm{Au}$ atom, while the dissociation adsorption of $\mathrm{N}-\mathrm{O}$ bonds on the $\mathrm{C}-\mathrm{Au}(211)$ surface occurs on a carbon atom and the adjacent Au site. The conformation of the $\mathrm{N}$ atom shows a noticeable distortion from planarity. Selective adsorption and dissociation of the nitro group appear to occur naturally. 


\section{Discussion}

It is obvious that interstitial $\mathrm{C}$ can be produced in the Au lattice during the carbonization of an ordered mesoporous carbon carrier, and plays a vital role in selective hydrogenation. First, $\mathrm{H}_{2}$ molecules can be activated. The heterolytic dissociation of $\mathrm{H}_{2}$ can take place on $\mathrm{C}-\mathrm{Au}$ due to electron transfer between $\mathrm{C}$ and $\mathrm{Au}$. The adsorption configuration also implies a significant effect of the electronic properties of $\mathrm{C}-\mathrm{Au}$ on the chemisorption. This selective adsorption and activation on $\mathrm{Au}$ surfaces containing interstitial C compared to pure surfaces explains the high chemoselectivity observed for the $\mathrm{C}-\mathrm{Au} / \mathrm{OMC}$ catalysts compared to commercial $\mathrm{Au} / \mathrm{C}$ and $\mathrm{Au} / \mathrm{SiO}_{2}$. In addition, a continuous exchange of $\mathrm{C}$ atoms between surface and subsurface possibly occurs, which may facilitate the adsorption of $\mathrm{H}_{2}{ }^{39}$. The dynamics of $\mathrm{C}$ movement in the Au lattice may also be responsible for the desorption of products to inhibit accumulation on the surface, which enhances the reusability. The changes in solid state properties merely reflect the existence of a bound state for the absorbed intermediate that is energetically most favored for the catalytic reaction, and the entropy change is highly associated with this process. The inherent electronic energy for the entropy changes must involve the extent of occupation of the various bands ${ }^{65}$. As a result, the activation entropy and activity changes can be related to the distribution of $d$-band holes between the $t_{2 \mathrm{~g}}$ and $e_{\mathrm{g}}$ bands. A linear relationship has been plotted for the calculated changes in the activation entropy and TOF values vs the electron gain for the Au $d$ orbital (Fig. 5). The activation of the noble Au surface is achieved by the injection of $d$ electrons. It should be mentioned that $\mathrm{C}-\mathrm{Au}-3.9 / \mathrm{OMC}$ has a larger $d$-charge gain than $\mathrm{Au} / \mathrm{TiO}_{2}$ with a similar particle size. When comparing the TOF values for $\mathrm{C}-\mathrm{Au}-3.9 / \mathrm{OMC}$ and $\mathrm{Au} / \mathrm{TiO}_{2}$, they follow the same trend. The catalyst with the highest $d$-electron gain has the highest TOF $\left(670 \mathrm{~h}^{-1}\right)$, almost three times that of a commercial $\mathrm{Au} / \mathrm{TiO}_{2}$ catalyst and a $>99 \%$ selectivity to 3 -VA. By comparison, commercial $\mathrm{Au} / \mathrm{C}$ and $\mathrm{Au} / \mathrm{SiO}_{2}$ catalysts with an extremely low $d$ electron gain are almost inert.

In summary, an attempt has been made to boost catalytic hydrogenation by using gold nanocatalysts with $\mathrm{C}$ occupying interstitial sites in its lattice, which contributes to the electron transfer or redistribution at $\mathrm{Au}$ sites. These $\mathrm{C}-\mathrm{Au}$ catalysts with $d$-electron gain show a high chemoselective hydrogenation activity of the nitro group in 3-nitrostyrene even when supported on a less-active ordered mesoporous carbon. This strategy paves the way for the design of noble metal catalysts loaded on an industrially available carbon carrier with unique chemoselectivity in organic reactions.

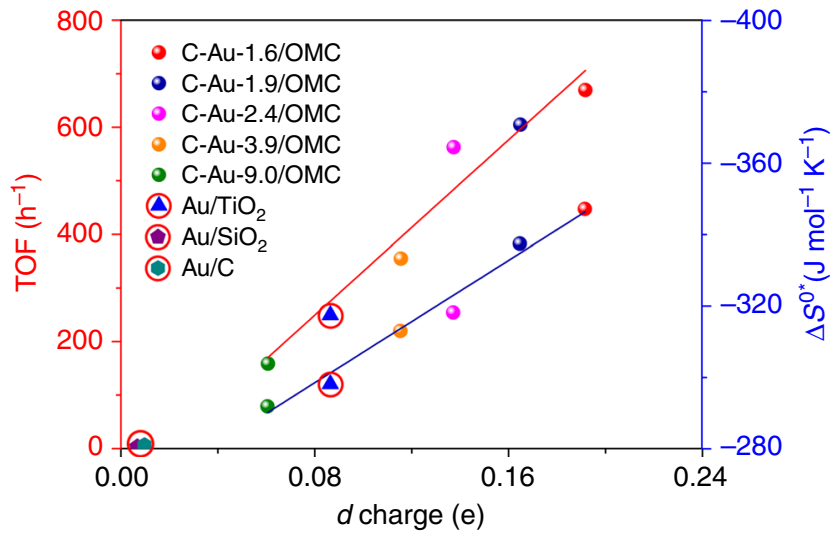

Fig. 5 Descriptor. The relationship between the $d$-electron gain at an $\mathrm{Au}$ site and the turn-over frequency (TOF, red line) and the entropy of activation $\left(\Delta S^{0 *}\right.$, navy line) for the selective hydrogenation of 3-NS.

\section{Methods}

Synthesis of C-Au/OMC. Au catalysts encapsulated in ordered mesoporous carbon nanospheres were synthesized using a hydrothermal method. In a typical synthesis, $0.6 \mathrm{~g}$ phenol (Macklin, AR), $15 \mathrm{~mL} \mathrm{NaOH}(0.1 \mathrm{M})$, and $2.1 \mathrm{~mL}$ formalin aqueous solution $(37 \mathrm{wt} \%)$ were mixed at $70{ }^{\circ} \mathrm{C}$ under a stirring speed of $360 \mathrm{rpm}$ for $30 \mathrm{~min}$. Then, a clear aqueous solution of $0.96 \mathrm{~g} \mathrm{F127}$ (Acros Chemical Inc., $\left.\mathrm{EO}_{106} \mathrm{PO}_{70} \mathrm{EO}_{106}, \mathrm{M}_{\mathrm{W}}=12,600 \mathrm{~g} \mathrm{~mol}^{-1}\right)$ in $15 \mathrm{~g}$ Milli-Q water was added to the solution, and the mixed solution was stirred at $67^{\circ} \mathrm{C}$ for further $2-4 \mathrm{~h}$. After that, a solution prepared by mixing $50 \mathrm{~g}$ Milli-Q water, $1.5 \mathrm{~mL} \mathrm{HAuCl}_{4}$ (gold concentration in water: $24.3 \mathrm{mmol} \mathrm{L}^{-1}$ ) and $0.128 \mathrm{~g}$ 3-mercaptopropyltrimethoxysilane (MPTMS, $85 \mathrm{wt} \%$ Acros Chemical Inc.) were added. The above reaction was immediately stopped by cooling the solution to room temperature when precipitation was observed in the solution. When the precipitate was dissolved after a short time of quiescence, the obtained solution was transferred into several autoclaves, diluted with $\mathrm{H}_{2} \mathrm{O}\left(3.16 \mathrm{~mL}\right.$ of water per $\mathrm{mL}$ of solution) and heated at $130{ }^{\circ} \mathrm{C}$ for $24 \mathrm{~h}$. A yellow solid was collected after centrifugation, washing with Milli-Q water and ethanol, and dried in a vacuum overnight at $80^{\circ} \mathrm{C}$. After carbonization at $700^{\circ} \mathrm{C}$ for $3 \mathrm{~h}$ under high-purity $\mathrm{N}_{2}$, which removed the triblock copolymer templates and carbonized the resins, and cooling at $200^{\circ} \mathrm{C}$ for $6 \mathrm{~h}$ in air a black product was obtained, which is denoted $\mathrm{C}-\mathrm{Au}-n / \mathrm{OMC}$, wherein $n$ represents the size of the gold particles measured by TEM. By changing the ratio between $\mathrm{HAuCl}_{4}$ and $\mathrm{MPTMS}$ and the carbonization temperature while keeping the other processing parameters constant, catalysts with gold particles ranging from 1.6 to $9.0 \mathrm{~nm}$ diameter were obtained (Supplementary Table 3). Customized reference Au catalysts including Au/ $\mathrm{TiO}_{2}, \mathrm{Au} / \mathrm{SiO}_{2}$, and $\mathrm{Au} / \mathrm{C}$ were purchased from Haruta Gold Inc. (Japan).

Characterization of the materials. The crystal structure of the catalysts was analyzed by WAXRD, which was performed on a Rigaku D max-3C diffractometer using $\mathrm{Cu} \mathrm{Ka}$ radiation. The morphology of the catalysts was characterized by HRSEM using a Hitachi S-4800 ultrahigh resolution cold FEG with an in-lens electron optic operating at $20 \mathrm{kV}$, and by TEM using a JEM 2100 microscope operating at $200 \mathrm{kV}$. Lattice resolution images of the Au catalysts were taken by HAADF-STEM, using a JEM-ARM $200 \mathrm{~F}$ microscope. The AC-STEM images were collected using a Titan Cubed Themis G2 300 microscope operated at $200 \mathrm{kV}$. A Micromeritics TriStar II 3020 analyzer was used to measure the $\mathrm{N}_{2}$ adsorption-desorption isotherms of the catalysts at $77 \mathrm{~K}$. The specific surface areas $\left(\mathrm{S}_{\mathrm{BET}}\right)$ and the pore size $\left(\mathrm{D}_{\mathrm{P}}\right)$ distributions of the catalysts were calculated using the BET method and the Barrett-Joyner-Halenda model. A double-crystal Si(111) monochromator was used for energy selection at both the Au $L_{3}$-edge $(11,919 \mathrm{eV})$. A Lytle detector was used to collect data in the fluorescent mode at room temperature, and XAS data were processed using the Athena program. Individual scans were calibrated and aligned using an Au foil spectrum. Au $L_{3}$-edge extended X-ray absorption fine structure processing data were fitted using the software package for the inverse fast Fourier transform (IFEFFIT) in R space. XPS was used to characterize the chemical composition and elemental state of the catalysts on a PerkinElmer PHI 5000 CESCA instrument. For the XPS studies, a Al Ka source was used. A pass energy of $40 \mathrm{eV}$ and a step size of $100 \mathrm{meV}$ were used for a survey scan. An experimental resolution of $0.5 \mathrm{eV}$ has been fitted from the $\mathrm{Ag} 3 d_{5 / 2}$ bulk peak. For a detailed analysis, the core-level lines obtained by XPS were numerically fitted by a convolution of a Gaussian and a Lorentzian profile with an additional parameter allowing asymmetry of the line, and the data were calibrated using the $\mathrm{C} 1 \mathrm{~s}$ binding energy of $284.6 \mathrm{eV}$.

The $\mathrm{Au}$ content of the catalysts was determined using a Varian VISTAMPX inductively coupled plasma-atomic emission spectrometer.

Catalytic activity tests: the hydrogenation reactions of 3-nitrostyrene (Acros, $97 \mathrm{wt} \%$ ) were performed in a $50 \mathrm{~mL}$ autoclave equipped with a Teflon tube (Parr) Normally, the autoclave was loaded with $0.41 \mathrm{mmol} 3-\mathrm{NS}, 5 \mathrm{~mL}$ ethanol, and the $\mathrm{C}-\mathrm{Au} / \mathrm{OMC}$ catalyst and then flushed three times with $0.5 \mathrm{MPa} \mathrm{H}_{2}$ before it was pressurized to the desired $\mathrm{H}_{2}$ pressure of $4.0 \mathrm{MPa}$ and then placed in an oil bath maintained at the reaction temperature of $140{ }^{\circ} \mathrm{C}$. The stirring rate was set to 800 rpm to eliminate any external diffusion. The reaction was stopped at a selected time by immediately cooling the autoclave in an ice-water bath. The solid catalysts were collected by filtration and then washed with Milli-Q water and dried at $80^{\circ} \mathrm{C}$. The collected filtrate was extracted with $20 \mathrm{~mL}$ of ethanol. Analysis of the reaction products was done on an Agilent $7890 \mathrm{~B}$ gas chromatograph equipped with a DB-1 capillary column $(30.0 \mathrm{~m} \times 320 \mathrm{~mm} \times 0.25 \mathrm{~mm})$ and a flame ionization detector. Each reaction test was repeated at least three times with an experimental error of \pm $5 \%$. Based on the conversion of 3-NS, the yields of 3-VA and 3-EA were given as the results of the reaction. The reaction with deuterium gas was the same as above with the hydrogen replaced by $\mathrm{D}_{2}$. The catalytic activity results were given in terms of the conversion of 3-NS, yield of 3-VA and 3-EA, initial reaction rate (molecules of 3-NS converted per mole of Au per hour), and TOF (molecules of 3-NS converted per surface atom of Au per hour). The TOF value was calculated at a conversion below $25 \%$ and was reproducible to within $\pm 5 \%$. An established method was used to calculate the exposed surface area of the dispersed $\mathrm{Au}$ particles $^{66}$.

The TOF, $E_{\mathrm{a}}, \Delta S^{0 *}$, and the elemental reaction steps for the hydrogenation reactions of 3-nitrostyrene over $\mathrm{C}-\mathrm{Au} / \mathrm{OMC}$ catalysts were obtained and are described in the Supplementary information. 
Mass transfer limitation tests: the tests were carried out under the same reaction conditions as already described. External mass transfer limitations are avoided by using different stirring speeds in the range 600-1000 rpm (Supplementary Fig. 13). The Madon-Boudart tests using $20 \mathrm{mg}$ of C-Au-2.4/OMC catalyst with similar $\mathrm{Au}$ dispersions but different $\mathrm{Au}$ concentrations ranging from $0.5-1.0 \mathrm{wt} \%$ were performed to investigate the internal diffusion limitation. A linear relationship between the initial reaction rate and $\mathrm{Au}$ concentration indicated the absence of a mass transfer effect under the reaction conditions (Supplementary Fig. 15).

Recycling tests: the recycling hydrogenation reaction of 3-NS was carried out over $\mathrm{C}-\mathrm{Au}-2.4 / \mathrm{OMC}$ catalyst under the reaction conditions described above. After each run, the $\mathrm{C}-\mathrm{Au}-2.4 / \mathrm{OMC}$ catalyst was recovered after thoroughly washing with copious amounts of ethanol and water, and drying under vacuum at $80^{\circ} \mathrm{C}$ overnight. In order to maintain the same amount of catalyst in each run, several parallel reactions were carried out at the same time. The gold contents of the solid as well as in the aqueous solution after each cycle were determined.

Trapping tests: thiol group-modified mesoporous silica (SH-SBA-15, Supplementary information) with a molar ratio of $\mathrm{SH}: \mathrm{Au}=35: 1$ was used to capture any soluble gold species that had leached into the solution during the reactions and to investigate the stability of the gold catalysts ${ }^{59}$.

DFT calculations: DFT calculations were carried out with the Vienna ab initio simulation package ${ }^{67}$. The $\mathrm{Au}(111)$ and (211) surfaces were modeled using a fivelayer metal slab describing a $p(2 \times 2)$ unit cell and a vacuum layer of $12 \AA$. The relative positions of the atoms are as in the bulk, with an optimized lattice parameter of $4.17 \AA$, which is close to the previously experimental and the calculated ones (i.e., 4.08 and $4.17 \AA$, respectively) ${ }^{68}$. Three different surface sites (top, bridge, and hollow) and two different subsurface sites (tetrahedral and octahedral) were considered. More details are presented in the Supplementary information (computational details and Tables 4-8).

\section{Data availability}

The data that support the findings of this study are available from the corresponding authors upon reasonable request.

Received: 28 March 2020; Accepted: 10 August 2020;

Published online: 14 September 2020

\section{References}

1. Hammer, B. \& Norskov, J. K. Why gold is the noblest of all the metals. Nature 376, 238-240 (1995).

2. Ferrin, P., Kandoi, S., Nilekar, A. U. \& Mavrikakis, M. Hydrogen adsorption, absorption and diffusion on and in transition metal surfaces: a DFT study. Surf. Sci. 606, 679-689 (2012).

3. Zhang, L., Zhou, M., Wang, A. \& Zhang, T. Selective hydrogenation over supported metal catalysts: from nanoparticles to single atoms. Chem. Rev. 120, 683-733 (2020).

4. Visikovskiy, A. et al. Electronic $d$-band properties of gold nanoclusters grown on amorphous carbon. Phys. Rev. B 83, 165428 (2011).

5. Villa, A. et al. Characterisation of gold catalysts. Chem. Soc. Rev. 45, 4953-4994 (2016).

6. Corma, A. \& Serna, P. Chemoselective hydrogenation of nitro compounds with supported gold catalysts. Science 313, 332-334 (2006).

7. Jenkins, A. H., Musgrave, C. B. \& Medlin, J. W. Enhancing Au/TiO 2 catalyst thermostability and coking resistance with alkyl phosphonic-acid selfassembled monolayers. ACS Appl. Mater. Interfaces 11, 41289-41296 (2019).

8. Shao, Z. J., Zhang, L., Liu, H., Cao, X. M. \& Hu, P. Enhanced interfacial $\mathrm{H}_{2}$ activation for nitrostyrene catalytic hydrogenation over rutile titaniasupported gold by coadsorption: a first-principles microkinetic simulation study. ACS Catal. 9, 11288-11301 (2019).

9. Wang, L. et al. Activity and selectivity in nitroarene hydrogenation over $\mathrm{Au}$ nanoparticles on the edge/corner of anatase. ACS Catal. 6, 4110-4116 (2016).

10. Serna, P., Boronat, M. \& Corma, A. Tuning the behavior of Au and Pt catalysts for the chemoselective hydrogenation of nitroaromatic compounds. Top. Catal. 54, 439-446 (2011).

11. Boronat, M. et al. A molecular mechanism for the chemoselective hydrogenation of substituted nitroaromatics with nanoparticles of gold on $\mathrm{TiO}_{2}$ catalysts: a cooperative effect between gold and the support. J. Am. Chem. Soc. 129, 16230-16237 (2007).

12. Roldan Cuenya, B. Metal nanoparticle catalysts beginning to shape-up. Acc. Chem. Res. 46, 1682-1691 (2013).

13. Fujitani, T., Nakamura, I., Akita, T., Okumura, M. \& Haruta, M. Hydrogen dissociation by gold clusters. Angew. Chem. Int. Ed. 48, 9515-9518 (2009).

14. Yang, B., Cao, X. M., Gong, X. Q. \& Hu, P. A density functional theory study of hydrogen dissociation and diffusion at the perimeter sites of $\mathrm{Au} / \mathrm{TiO}_{2}$. Phys. Chem. Chem. Phys. 14, 3741-3745 (2012).
15. Zhang, L., Cao, X. M. \& Hu, P. Insight into chemoselectivity of nitroarene hydrogenation: a DFT- $\mathrm{D}_{3}$ study of nitroarene adsorption on metal surfaces under the realistic reaction conditions. Appl. Surf. Sci. 392, 456-471 (2017).

16. Park, Y. S. et al. Contact chemistry and single-molecule conductance: a comparison of phosphines, methyl sulfides, and amines. J. Am. Chem. Soc. 129, 15768-15769 (2007).

17. Jiang, Z. et al. Direct XPS evidence for charge transfer from a reduced rutile $\mathrm{TiO}_{2}(110)$ surface to Au clusters. J. Phys. Chem. C 111, 12434-12439 (2007).

18. Wu, Y., Sun, K. Q., Yu, J. \& Xu, B. Q. A key to the storage stability of Au/TiO catalyst. Phys. Chem. Chem. Phys. 10, 6399-6404 (2008).

19. Honkala, K. Tailoring oxide properties: an impact on adsorption characteristics of molecules and metals. Surf. Sci. Rep. 69, 366-388 (2014).

20. Ishida, T., Murayama, T., Taketoshi, A. \& Haruta, M. Importance of size and contact structure of gold nanoparticles for the genesis of unique catalytic processes. Chem. Rev. 120, 464-525 (2020).

21. Liu, F. et al. Ordered mesoporous polymers for biomass conversions and cross-coupling reactions. ChemSusChem 9, 2496-2504 (2016).

22. Ariga, K., Vinu, A., Yamauchi, Y., Ji, Q. \& Hill, J. P. Nanoarchitectonics for mesoporous materials. Bull. Chem. Soc. Jpn. 85, 1-32 (2011).

23. Benzigar, M. R. et al. Recent advances in functionalized micro and mesoporous carbon materials: synthesis and applications. Chem. Soc. Rev. 47, 2680-2721 (2018).

24. Maruyama, T. et al. Single-walled carbon nanotube synthesis using Pt catalysts under low ethanol pressure via cold-wall chemical vapor deposition in high vacuum. Carbon 96, 6-13 (2016).

25. Guo, R. et al. $\mathrm{PdC}_{\mathrm{x}}$ nanocrystals with tunable compositions for alkyne semihydrogenation. J. Mater. Chem. A 7, 4714-4720 (2019).

26. Teschner, D. et al. The roles of subsurface carbon and hydrogen in palladiumcatalyzed alkyne hydrogenation. Science 320, 86-89 (2008).

27. Yang, B., Burch, R., Hardacre, C., Headdock, G. \& Hu, P. Influence of surface structures, subsurface carbon and hydrogen, and surface alloying on the activity and selectivity of acetylene hydrogenation on Pd surfaces: a density functional theory study. J. Catal. 305, 264-276 (2013).

28. Yudanov, I. V., Neyman, K. M. \& Rösch, N. Density functional study of Pd nanoparticles with subsurface impurities of light element atoms. Phys. Chem. Chem. Phys. 6, 116-123 (2004).

29. Chen, S. et al. Poison tolerance to the selective hydrogenation of cinnamaldehyde in water over an ordered mesoporous carbonaceous composite supported Pd catalyst. ACS Catal. 7, 2074-2087 (2017).

30. Piqué, O. et al. Subsurface carbon: a general feature of noble metals. Angew. Chem. Int. Ed. 58, 1744-1748 (2019).

31. Fu, H., Zhang, L., Wang, Y., Chen, S. \& Wan, Y. Thermally reduced gold nanocatalysts prepared by the carbonization of ordered mesoporous carbon as a heterogeneous catalyst for the selective reduction of aromatic nitro compounds. J. Catal. 344, 313-324 (2016).

32. Zhu, X. et al. Optimising surface $d$ charge of AuPd nanoalloy catalysts for enhanced catalytic activity. Nat. Commun. 10, 1428 (2019).

33. Qi, W. H. \& Wang, M. P. Size and shape dependent lattice parameters of metallic nanoparticles. J. Nanopart. Res. 7, 51-57 (2005).

34. Takagi, D., Kobayashi, Y., Hibino, H., Suzuki, S. \& Homma, Y. Mechanism of gold-catalyzed carbon material growth. Nano Lett. 8, 832-835 (2008).

35. Tang, D. M. et al. Structural changes in Iron oxide and gold catalysts during nucleation of carbon nanotubes studied by in situ transmission electron microscopy. ACS Nano 8, 292-301 (2014).

36. Jacobson, N. S., Savadkouei, K., Morin, C., Fenstad, J. \& Copland, E. H. Combustion methods for measuring low levels of carbon in nickel, copper, silver, and gold. Metall. Mater. Trans. B 47, 3533-3543 (2016).

37. Yazyev, O. V. \& Pasquarello, A. Effect of metal elements in catalytic growth of carbon nanotubes. Phys. Rev. Lett. 100, 156102 (2008)

38. Ali, S., Myasnichenko, V. S. \& Neyts, E. C. Size-dependent strain and surface energies of gold nanoclusters. Phys. Chem. Chem. Phys. 18, 792-800 (2016).

39. Martínez, B., Piqué, O., Prats, H., Viñes, F. \& Illas, F. Towards understanding the role of carbon atoms on transition metal surfaces: implications for catalysis. Appl. Surf. Sci. 513, 145765 (2020).

40. Chenakin, S. \& Kruse, N. Combining XPS and ToF-SIMS for assessing the CO oxidation activity of $\mathrm{Au} / \mathrm{TiO}_{2}$ catalysts. J. Catal. 358, 224-236 (2018).

41. Peters, S., Peredkov, S., Neeb, M., Eberhardt, W. \& Al-Hada, M. Sizedependent XPS spectra of small supported Au-clusters. Surf. Sci. 608, 129-134 (2013).

42. Zeng, Z., Ma, X., Ding, W. \& Li, W. First-principles calculation of core-level binding energy shift in surface chemical processes. Sci. China Chem. 53, 402-410 (2010).

43. Viñes, F., Gomes, J. R. B. \& Illas, F. Understanding the reactivity of metallic nanoparticles: beyond the extended surface model for catalysis. Chem. Soc. Rev. 43, 4922-4939 (2014).

44. Benfield, R. E. et al. Structure and bonding of gold metal clusters, colloids, and nanowires studied by EXAFS, XANES, and WAXS. J. Phys. Chem. B 105, 1961-1970 (2001). 
45. Zhang, P. \& Sham, T. K. Tuning the electronic behavior of Au nanoparticles with capping molecules. Appl. Phys. Lett. 81, 736-738 (2002).

46. Schwartz, V. et al. XAS study of Au supported on $\mathrm{TiO}_{2}$ : influence of oxidation state and particle size on catalytic activity. J. Phys. Chem. B 108, 15782-15790 (2004).

47. Liu, S. et al. Ultrastable Au nanoparticles on titania through an encapsulation strategy under oxidative atmosphere. Nat. Commun. 10, 5790 (2019).

48. Coulthard, I. \& Sham, T. K. Charge redistribution in Pd-Ag alloys from a local perspective. Phys. Rev. Lett. 77, 4824-4827 (1996).

49. Mason, M. G. Electronic structure of supported small metal clusters. Phys. Rev. B 27, 748-762 (1983).

50. Suntivich, J., May, K. J., Gasteiger, H. A., Goodenough, J. B. \& Shao-Horn, Y. A perovskite oxide optimized for oxygen evolution catalysis from molecular orbital principles. Science 334, 1383-1385 (2011).

51. Kaden, W. E., Wu, T., Kunkel, W. A. \& Anderson, S. L. Electronic structure controls reactivity of size-selected $\mathrm{Pd}$ clusters adsorbed on $\mathrm{TiO}_{2}$ surfaces. Science 326, 826-829 (2009).

52. Greiner, M. T. et al. Free-atom-like $d$ states in single-atom alloy catalysts. Nat. Chem. 10, 1008-1015 (2018).

53. Lykhach, Y. et al. Counting electrons on supported nanoparticles. Nat. Mater. 15, 284-288 (2016).

54. Greaves, G. N., Durham, P. J., Diakun, G. \& Quinn, P. Near-edge X-ray absorption spectra for metallic $\mathrm{Cu}$ and $\mathrm{Mn}$. Nature 294, 139-142 (1981).

55. Koizumi, Y. et al. Selective synthesis of primary anilines from $\mathrm{NH}_{3}$ and cyclohexanones by utilizing preferential adsorption of styrene on the Pd nanoparticle surface. Angew. Chem. Int. Ed. 58, 10893-10897 (2019).

56. Serna, P. \& Corma, A. Transforming nano metal nonselective particulates into chemoselective catalysts for hydrogenation of substituted nitrobenzenes. ACS Catal. 5, 7114-7121 (2015).

57. Sun, K. Q., Hong, Y. C., Zhang, G. R. \& Xu, B. Q. Synergy between Pt and Au in Pt-on-Au nanostructures for chemoselective hydrogenation catalysis. ACS Catal. 1, 1336-1346 (2011).

58. Madon, R. J. \& Boudart, M. Experimental criterion for the absence of artifacts in the measurement of rates of heterogeneous catalytic reactions. Ind. Eng. Chem. Fundam. 21, 438-447 (1982).

59. Richardson, J. M. \& Jones, C. W. Strong evidence of solution-phase catalysis associated with palladium leaching from immobilized thiols during Heck and Suzuki coupling of aryl iodides, bromides, and chlorides. J. Catal. 251, 80-93 (2007).

60. Serna, P., Concepción, P. \& Corma, A. Design of highly active and chemoselective bimetallic gold-platinum hydrogenation catalysts through kinetic and isotopic studies. J. Catal. 265, 19-25 (2009).

61. Schnadt, J. et al. Experimental evidence for sub-3-fs charge transfer from an aromatic adsorbate to a semiconductor. Nature 418, 620-623 (2002).

62. Li, J. et al. Two distinctive energy migration pathways of monolayer molecules on metal nanoparticle surfaces. Nat. Commun. 7, 10749 (2016).

63. Van Bokhoven, J. J. G. M., Kuiper, A. E. T. \& Medema, J. The role of heterogeneity in the kinetics of a surface reaction: III. Distributions in activation enthalpy and entropy. J. Catal. 43, 181-191 (1976).

64. Sun, K., Kohyama, M., Tanaka, S. \& Takeda, S. A study on the mechanism for $\mathrm{H}_{2}$ dissociation on $\mathrm{Au} / \mathrm{TiO}_{2}$ catalysts. J. Phys. Chem. C 118, 1611-1617 (2014).

65. Chen, W. et al. Mechanistic and kinetic insights into the Pt-Ru synergy during hydrogen generation from ammonia borane over PtRu/CNT nanocatalysts. J. Catal. 356, 186-196 (2017).

66. Chen, W. et al. Mechanistic insight into size-dependent activity and durability in Pt/CNT catalyzed hydrolytic dehydrogenation of ammonia borane. J. Am. Chem. Soc. 136, 16736-16739 (2014)
67. Kresse, G. \& Furthmüller, J. Efficiency of ab-initio total energy calculations for metals and semiconductors using a plane-wave basis set. Comput. Mater. Sci. 6, 15-50 (1996)

68. Rankin, R. B. \& Greeley, J. Trends in selective hydrogen peroxide production on transition metal surfaces from first principles. ACS Catal. 2, 2664-2672 (2012).

\section{Acknowledgements}

This work was supported by the National Natural Science Foundation of China (21773156, 21503136), the Ministry of Education of China (PCSIRT_IRT_16R49), the International Joint Laboratory on Resource Chemistry of China (IJLRC), the Shanghai Sci. \& Tech. and Edu. Committee (17JC1404200) and the Shanghai Gaofeng \& Gaoyuan Project for University Academic Program Development.

\section{Author contributions}

Y.W. designed the research, supervised experiments, and edited the paper. Y.F.S., Y.Q.C., and L.L.W. planned synthesis and tested catalysts, analyzed the XAS and kinetics data and wrote the paper. X.T.M. analyzed the XPS data, performed the XRD and BET characterizations and edited the figures. Q.F.Z. performed the TEM and EDX experiments and data analysis. R.S. performed the XAS experiments and data analysis. X.J.Z and S.J.C. edited the figures. B.S.Z performed the HAADF-STEM. Y.Q.C. and D.C. contributed to the DFT calculations and discussion on the kinetics. All authors discussed the results and commented on the paper.

\section{Competing interests}

The authors declare no competing interests.

\section{Additional information}

Supplementary information is available for this paper at https://doi.org/10.1038/s41467 020-18322-x.

Correspondence and requests for materials should be addressed to Y.W.

Peer review information Nature Communications thanks the anonymous reviewer(s) for their contribution to the peer review of this work. Peer reviewer reports are available.

Reprints and permission information is available at http://www.nature.com/reprints

Publisher's note Springer Nature remains neutral with regard to jurisdictional claims in published maps and institutional affiliations.

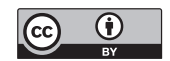

Open Access This article is licensed under a Creative Commons Attribution 4.0 International License, which permits use, sharing, adaptation, distribution and reproduction in any medium or format, as long as you give appropriate credit to the original author(s) and the source, provide a link to the Creative Commons license, and indicate if changes were made. The images or other third party material in this article are included in the article's Creative Commons license, unless indicated otherwise in a credit line to the material. If material is not included in the article's Creative Commons license and your intended use is not permitted by statutory regulation or exceeds the permitted use, you will need to obtain permission directly from the copyright holder. To view a copy of this license, visit http://creativecommons.org/ licenses/by/4.0\%

(C) The Author(s) 2020 